\title{
Comunicación para el Desarrollo Humano: buscando la transformación social
}

\author{
Raquel Martínez-Gómez y Pinar Agudiez*
}

Propuesto: 11 de marzo de 2012

Evaluado: 2 de mayo de 2012

Aceptado: 5 de mayo de 2012

(Abstracts y palabras clave al final del texto)

\begin{abstract}
...Todos somos básicamente idénticos. Al menos en teoría, cualquiera podría ponerse en el sitio de cualquiera. (Aunque... nuestra mente también es capaz de producir ideas que paralizan esta tendencia natural a la empatía: el racismo, el sexismo, la xenofobia, la homofobia, el nacionalismo, todas esas perversas exaltaciones de las pequeñas diferencias.)", Jorge Volpi, Leer la mente.
\end{abstract}

\section{INTRODUCCIÓN: EN BUSCA DE LOS SENTIDOS}

Siempre tuvo sentido hablar de comunicación, transformación social y desarro1lo, aunque quizá la coyuntura actual aporta un escenario más propicio si cabe debido a las crisis de emergencia medioambiental, inequidad galopante y dominación cultural, todas ellas relacionadas. La paradoja la sirve un modelo que coqueteó desde sus inicios con la idea de progreso, pero que despuntando el siglo XXI vuelve a dejar en evidencia sus logros. La crisis del capitalismo - ya reconocida hasta por el Financial Times -, llevaba años proclamándose desde diferentes ámbitos de la sociedad (académicos, sociedad civil...), pero no ha sido hasta ahora cuando los voceros del poder empiezan a asombrarse de aquello que ya se sabía. En este artículo no queremos pasar por alto el contexto donde se ha dejado al mercado, cada vez con menos límites, el bienestar de las sociedades porque fue el facilitador de una estructura donde los flujos de comunicación e información fueron puestos al servicio del capital, es decir, de una lógica que garantiza la búsqueda del beneficio económico para unos pocos. Por ende, se trata de un marco que impide el desarrollo de

* Raquel Martínez - Gómez López. Doctora en Ciencias de la Información y escritora. Pinar Agudiez Calvo. Profesora Titular Facultad de Ciencias de la Información (UCM). 
la capacidad transformadora de la comunicación y que anula la posibilidad de que ésta sirva de fundamento de unas relaciones sociales donde primen la cooperación y la equidad.

Al reflexionar sobre la reforma de la gobernanza global, David Held (2005: 135136) nos invita a pensar en el impacto que la toma unidireccional de decisiones de las elites u oligarquías poderosas puede tener en la gente. Sobre la esperanza de vida, cuando afectan a necesidades o intereses que van desde la salud a la vivienda, por ejemplo. Sobre la calidad de las opciones vitales, cuando las necesidades se ven afectadas de tal modo que se pone en cuestión la capacidad de las personas para ser partícipes en las actividades económicas, políticas y culturales de su comunidad. Sobre las formas de vida o en el abanico de opciones de consumo disponibles. Estas categorías, proporcionan algunas orientaciones útiles: en primer lugar, si no se responde a las necesidades urgentes de las personas, sus vidas correrán peligro. En segundo lugar, si no se responde a sus necesidades secundarias, tampoco podrán participar totalmente en sus comunidades y sus posibilidades de implicarse en la vida pública y privada seguirán sin consumarse; sus opciones se verán restringidas o reducidas. En consecuencia, las oportunidades vitales de los seres humanos corren el riesgo de sufrir daños. En tercer lugar, si no se responde a las necesidades relativas a la forma de vida, la ciudadanía verá frustrada su capacidad para desarrollar su existencia y expresarse. Las tensiones y conflictos graves que puedan derivar de la frustración generada por la insatisfacción de estas necesidades no debemos minusvalorarla. Es preciso, anota Held, reformular los principios de inclusión y subsidiariedad en o para la gobernanza global pues, en su opinión, significa que aquellos cuya esperanza de vida y opciones vitales se vean severamente afectadas deberían poder opinar sobe sus condiciones y regulación.

No es extraño entonces que el arrastre, y descalabro, hacia paradigmas económico-financieros derivase en otra vieja crisis, la de la democracia representativa. Si lo que engrasa las bisagras de la democracia es el diálogo, pero lo que se eligió fue el simulacro del diálogo, derivado de un modelo de comunicación inoperante y vertical, la farsa está servida. No deja de ser perturbador el silencio mediáticocorporativo-transnacional con el que se ha cubierto a algunas voces de la elite intelectual más crítica con la globalización. Por ejemplo, la de Jürgen Habermas. En $2007^{1}$ manifestaba:

Inmerso en uno de los ambientes de bienestar más deslumbrantes sigo sintiendo la creciente pobreza en que están los niños, el aumento de las disparidades en la distribución de ingresos y patrimonios, el crecimiento del sector de bajos salarios con una ocupación insegura, el segmento cada vez mayor de personas que se sienten superfluas, todo eso lo siento como un escándalo. Pero este escándalo debería ser entendido como una parte de los problemas que sólo podemos solucionar si invertimos esa tendencia, planetaria, a que los mercados escapen a las posibilidades de configuración política (Habermas, 2009:106).

1 En un texto que le serviría de base para el informe introductorio a una conversación con el Ministro de Asuntos Exteriores Frank-Walter Steinmeier (por invitación del Foro Cultural del SPD, el 23 de noviembre de 2007 en la Willy-Brand-Haus de Berlín). 
No basta con el reconocimiento explícito, con el discurso de la participación ciudadana: sin la articulación de todos los procesos relacionados con el derecho de comunicación, la construcción de lo democrático sin repensar los puntos sensibles de la responsabilidad, el juicio, la acción, el pensar como ejercicio de libertad, la polis interna: las doximatas ${ }^{2}$, la ideología, la pre-política - esa forma inicial de la violencia - (Roiz, 2003) se asemeja a un espacio vacío. Un estado donde los sentidos comunicacionales van desapareciendo al tiempo que la estera de lo público va destejiéndose - en algunas ocasiones desde construcciones muy precarias- - Las políticas de comunicación, dejadas a las leyes del "libre mercado" o al mercadeo de la lucha partidista, impiden que la comunicación sirva como guía o filosofía indispensable para la convivencia capaz de convocarnos a una "reconfiguración radical de las instituciones y de los discursos sociales, educativos y políticos para que sean capaces de responder a las necesidades del creciente número de comunidades constituidas por diferentes culturas que están proliferando en sus estados-naciones y en sus formaciones supranacionales" (Karavanta, 2011:16). En vez de anclar a la sociedad, haciendo que la comunicación sirva de "brújula" del intercambio, abriendo espacios a la creación y al aprendizaje, las élites - desde la manipulación, la ignorancia o la simple inercia - la vaciaron de sentido para "ocuparla" con las tareas propias de otros conceptos: periodismo, marketing, publicidad..., o para llenarla de su concepción de "herramienta tecnológica". Incluso desde la cooperación para el desarrollo, como ya nos recuerda Rosa María Alfaro (2006: 7), se recurrió a planteamientos simplistas "que restaron capacidad a cualquier intervención par ir construyendo espacios de cambio social". Una concepción que, por ejemplo, en el espacio de las ONGD españolas va superándose con mucha dificultad.

Como intentaremos deshilvanar en este artículo, sin otra mirada "no economicista" ni tecnológica de la comunicación, y sin una comprensión más ligada a lo que implica el largo plazo y más flexible con lo que supone el desarrollo, no se podrá siquiera dilucidar un proyecto de cooperación entre personas, localidades o estados que parta de relaciones entre iguales, sin subordinaciones. Porque hoy la exclusión y la inequidad nos separan. No es sólo una cuestión de salvaguardar las conquistas en materia social para una parte del mundo conseguidas desde la Revolución Francesa con el sudor de todas las batallas y muchas derrotas, sino también de construir otro modelo de sociedad sobre esta exhumación, que coadyuvará al descubrimiento de la memoria histórica, de otro modelo social. O retornar, sin duda, hacia el ser humano "allí donde no esperamos encontrarlo, esto es, en su vulnerabilidad y en los límites de su capacidad de tener sentido" (Butler, 2006).

Inserto en este contexto delimitaremos algunos planteamientos epistemológicos del ámbito postdisciplinario, o si se prefiere multidisciplinario, de la comunicación para el desarrollo. Partimos de la idea de que ésta, como campo profesional, está más sustentada en múltiples prácticas que en reflexiones o precisiones conceptuales

\footnotetext{
2 Que según Eric Voegelin están relacionadas con la opinión individual, con aquella que no contempla los hechos teniendo en cuenta las percepciones e ideas de los conciudadanos. A partir de ellas se pueden emitir las leyes de hierro de historia segmentada que introduzcan a los demás a un estado de opinión deseado por el pensador dóxico que las introduce (Roiz: 2000; 50).
} 
(Alfaro, 2006: 22) y que no se puede concebir su espacio sin su entronque con modelos educativos y culturales. Entre la cultura, la comunicación y la educación aparecen intersecciones y relaciones estrechas, complementarias, y en muchos casos dependientes, donde quedan diluidas las barreras que, en ocasiones, impone la obsesión más ortodoxa por señalar fronteras estériles entre las disciplinas. La separación entre unas políticas y otras, y en el caso de la comunicación su dejadez al "laissez faire", ha contribuido a debilitar las señas de entidad de un proyecto común.

Sabemos y valoramos otras propuestas, pero consideramos adecuado seguir hablando de desarrollo humano. El término nos parece lo suficientemente respaldado teóricamente, y además, si se entiende desde su enlace con las nociones que amplían sus limitaciones más economicistas, como las de Amartya Sen o las enunciaciones de Rosa María Alfaro, recoge un espíritu transformador que mueve hilos en la misma dirección que la comunicación para el cambio social. Alfaro lo describe como "palabra compartida en la acción de trasformar, construyendo nuevos sentidos comunes" (Alfaro, 2006: 19). Con ello no se trata de invalidar la utilización de otros conceptos como el "buen vivir", aunque no lo consideramos tan diferente. El hombre bueno y el buen ciudadano caminan juntos. La democracia es comunicación y se funda en la comunicación.

Si entendiéramos la democracia a la manera griega como isegoría, es decir, como la oportunidad real de cada ciudadano de decir en público lo que piensa difícilmente podríamos calificar de democracias a los sistema políticos de nuestro entorno. Hagamos al menos, el esfuerzo de pensar qué tipo de régimen político es uno que, tras un fondo de mil murmullos, se basa en unas pocas voces, del que ha desaparecido casi por completo la gran invención griega, la palabra libre, al alcance de todos (Sotelo, 1999: 16).

La articulación de la comunicación es el elemento clave, el aspecto más decisivo de la democracia (Arenas-Dolz, 2008). Todo un dispositivo retórico aristotélico al servicio de la construcción de la ciudad justa y del buen gobierno de uno mismo. Y un trabajo deliberativo que para la vida en democracia algunos ven como proyecto innovador (Arenas-Dolz, 2010) y otros como una renovación de la misma: "La deliberación trasladada al ámbito político implica una exigente concreción del ideal participativo que encarna la noción de democracia" (Velasco, 2009: 16). Ámbito que conviene recordar no es el conformado por los partidos políticos. Aceptar o desechar un término necesita de un ejercicio definitorio libre de prejuicios y comprometido con su propia definición, y ese es el esfuerzo que trataremos de realizar en estas páginas.

Trataremos de acercar y no de confrontar el concepto de comunicación para el desarrollo (utilizado mayormente en el sector de la cooperación para el desarrollo, aunque atañe a lo que ocurre dentro y fuera de cualquier frontera) a otros que han sido precisados como "comunicación para el cambio social" (Gumucio, 2004), o "comunicación comunitaria" (Kaplún, 2007) 3 porque consideramos que estamos hablando de

3 El apellido comunitario, como señala Kaplún (2007: 314), ha ido cobrando fuerza también como un modo de subrayar que entre estado y mercado hay otros modos de construir sociedad; que entre la representación política y el consumo hay otros modos de construir ciudadanía. 
cosas muy parecidas. Y en la parte más propositiva, recomendaremos que se profundice en la conceptualización de la comunicación como "espacio de diálogo". Si la voluntad es instalarse y fomentar procesos de transformación social, donde avance la equidad y la justicia, es necesario que la cultura dialógica penetre y sirva de guía a las instituciones políticas y sociales, empresas, universidades, sindicatos, ONGD, etc. No atender a este requisito del desarrollo humano supone reincidir en inercias reproductoras de las inequidades o en distopías. Objeto, este último, de preocupación en Mattelart (2009), cuya mirada nos hace retornar a la historia y a la memoria colectiva. Solamente una aproximación ciudadana que escape del elitismo, absteniéndose de hacer el juego populista, podría equilibrar la balanza respecto "al proyecto amnésico de la sociedad global de la información, a la mirada miope al imperativo categórico de la vuelta a la inversión a corto plazo", en términos de Mattelart. Es en la búsqueda de este nuevo contrato social donde reside el sentido de la lucha a favor de la transformación. "En realidad, la promesa de una nueva unión universal entre humanos gracias a la apropiación democrática del mundo tecnológico", señala Mattelart. El fracaso de esta utopía hecha realidad significaría, sin ninguna duda, dejar vía libre al desarrollo de nuevas formas autoritarias del ejercicio del poder, sentencia.

El derecho de los pueblos a comunicarse y "la apropiación democrática del mundo tecnológico" nos hace pensar en una reformulación contemporánea del dominio ejercido (y sus efectos) sobre la verdad, que siempre estuvo ligada a la cuestión del hombre. Sin duda, como señalaba Derrida (2005: 45), el estatus y los cambios de valor de la verdad pueden ser discutidos "ad infinitum" - fuere como adecuación, como revelación, como discurso teórico-constatativo o como acontecimiento poético-performativo...-. Dicho en otros términos, la colusión entre Discurso y Poder. Hoy, entre Conocimiento y Poder. Es, en el mismo orden de cosas, una puesta en suspensión de la Sociedad Digital del Conocimiento o de la Sociedad de la Información como promesa. Y una permanente puesta entre paréntesis del sentido último - ¿único? - de su prestación de servicios: $¡$ a quiénes sirven, en realidad, "los procesos de concentración capitalista en todos los sectores de la producción de recursos no materiales" (Mattelart, 2009)? En cualquier caso, nos remite a la intervención en el debate sobre el reciente proyecto de sociedad subyacente de nuevos actores sociales y de un sujeto histórico colectivo: los pueblos, que nos recuerda que comunicar es reciprocar actitudes - algo, por el momento, bastante incierto - Exigen estos actores, libertad de acceso porque sienten cercadas por los monopolios cognitivos las expresiones culturales y populares, que son silenciadas atacando directamente la diversidad y el pluralismo, la participación y la libertad; acometen definitoria y definitivamente el asalto al poder de la realidad; se declaran en este tiempo global, resistentes y hacen un trabajo de contrafuego. Como señala Virilio (1997: 78-79), para quien en un sentido amplio, la Ocupación hoy son las nuevas tecnologías y los medios de comunicación: "Yo hago de miembro de la resistencia porque hay demasiados "colaboracionistas" que una vez más atentan contra el progreso salvador, la emancipación y el hombre liberado de toda coacción (...)". Esta toma de posición o de regressus al sentido de la responsabilidad colectiva sobre aquellos bienes comunes y públicos se sitúa ya en el reinicio de una transformación social del espacio público, interrumpido o liquidado (el anterior intento transformador - pensemos en el requisito de la democratización de la información y en la asunción de la comunicación como derecho humano, relatos de la comunicación y el desarrollo en los años setenta y ochenta - desde y en las instituciones internacionales con la infatigable y eficaz ayuda de la agenda setting corporativo-transnacional), alterado/transformado ya por las tecnologías de 
la información y la comunicación, las técnicas de archivamiento, la producción de conocimiento y la distribución de la innovación traducida en recursos para la competitividad. "La globalización no se globaliza globalmente, por así decir, ni equitativamente para todos, lo que hace a esta nueva noción, así como a la retórica que la explota, sospechosa" (Cohen, 2005: 304).

Desde el conocimiento local a la acción transnacional, ésta es la transformación aún en estado latente de la comunicación como recurso - venimos de los paradigmas del desarrollo, estuvimos en las prácticas para el cambio social - para las transformaciones sociales cuyo axis mundi ya será el hombre. ¿Seremos capaces de encontrar una divergencia (Virilio, 1997); o un nuevo origen (Morin, 2010); tal vez un nuevo "sistema-mundo" (Ramonet, 2011); o un pensamiento de la coyuntura (Derrida, 1990); acaso valores y principios cosmopolitas (Held, 2005); oportunamente, un nuevo orden mundial (Habermas, 2009); o el pasaje gradual de una civilización antropocéntrica a una civilización biocéntrica (Foro Social Temático de Porto Alegre, 2012)? ¿Humanizar la globalización, entonces? ¿Acompañará la comunicación como intersección, como ligadura, como vínculo, como diálogo horizontal entre conocimientos? ¿Qué saber práctico demanda la teoría que aún no haya sido pensado? ¿Será preciso acordar un modelo de intervención interteórica sin que nadie se sienta subordinado epistémicamente por ello? ¿Qué tipo de comunicador pondrá en práctica la transformación social, con qué perfil, será un transformador social: educador, mediador, facilitador de procesos dialógicos en el espacio público o un metodólogo de la comunicación, un experto en cooperación para el desarrollo con la comunicación? ¿De qué formación precisará: filosofía del derecho, filosofía moral, semiótica, antropología social, economía del desarrollo, psicología cognitiva, ingenierías, derecho internacional público, sociología...? Cuando hablamos de empoderamiento, de participación, de comunidades locales, de un orden global o de la transformación de lo social, ¿en quiénes pensamos que puedan impulsar los cambios, encontrar las divergencias, traspasar las grietas, detectar las fisuras y actuar? Solos, desde la comunicación, no podemos. Pero solos desde el desarrollo tampoco.

Nuestro marco de análisis recorrerá dinámicas que van de lo local a lo global, si bien no prescindiremos de la dimensión estatal, porque es cierto que los marcos regulatorios del Estado-Nación siguen siendo imprescindibles para garantizar derechos universales dentro de ese camino hacia la utopía de la ciudadanía global, empoderada.

En definitiva, no es nuestra pretensión abordar la comunicación y el desarrollo operando desde la constatación. La complejidad del aquí y ahora toma nuestra mirada al asalto y pareciera proponernos generar una apertura, desde la comunicación, a cuyo través podamos llegar a observar un (otro) panorama mundial. Será precisa levantar otra perspectiva: la de un orden mundial nuevo que a su vez necesita de una nueva instalación: contextos de comunicación nacionales y transnacionales posibles en éste y para este tiempo de mediaciones y de precisiones o de transiciones, que la instantaneidad, la inmediatez y la ubicuidad convocan hasta convulsionar los relatos $^{4}$. Como los que ocuparon Wall Street, las plazas de Madrid, Barcelona, El

\footnotetext{
4 Recuperamos algunos pensamientos de José Jiménez Lozano (1990: 5-6) cuando escribe: "En el principio y desde el principio, fue el relato pequeño y testimonial de la existencia particular el único camino de acceso al saber sobre el mundo y los hombres (...) Y todo ello, como no puede ser de otro modo en el rela-
} 
Cairo... Un punto de partida en un trayecto, proactivo, reactivo que ponía en marcha la transformación de un mundo ruin en un mundo noble: una metáfora social. El pueblo habló. La comunicación no fue un simulacro.

\section{COMUNICACIÓN Y DESARROLLO HUMANO}

Si por algo se definen los conceptos de comunicación y desarrollo es por estar "en movimiento". Sus distintas dimensiones se inscriben en un camino sin paradas fijas, lo que no debería significar un obstáculo para el imprescindible ejercicio definitorio desde un aquí y un ahora que incorpore el saber acumulado y que nos comprometa con el diálogo del mañana.

Entendemos que no existe un consenso y que todavía abundan las reticencias al uso del concepto "comunicación para el desarrollo". Algunos critican la conjunción de los dos términos, otros la naturaleza del "desarrollo" por considerarlo integrado dentro de las mitologías occidentales o/y por simbolizar un modelo agotado. Incluso hay quienes lo identifican únicamente con la nomenclatura que distintas agencias de Naciones Unidas utilizan para nombrar la comunicación que se integra en las acciones y proyectos de desarrollo llevadas a cabo en los países donde operan. Pero recordemos que esta unión no es nueva, y que desde hace más de medio siglo distintas teorías y perspectivas (interpretativa, funcionalista, crítica) vinculan comunicación y desarrollo (muchas veces aludiendo al papel del Estado o a iniciativas de comunicación popular).

Reconstruyendo sus significados advertimos que el abuso y las contaminaciones que el poder hace del lenguaje no debieran anular su valor y que estamos ante fenómenos similares a los contenidos en otras terminologías como "comunicación comunitaria", "comunicación social alternativa", "democrática" "popular", "educativa", "de base" o "comunicación para el cambio social". Quizá cada uno proceda de una raíz diferente y tenga algunas ramas propias que lo hacen distinguirse de los demás, pero el tronco es común: todos encierran la esencia de una comunicación que pasaremos enseguida a describir, y todos contienen una semilla con voluntad transformadora.

La comunicación para el desarrollo busca el intercambio equitativo. Es decir, enlaza con la posibilidad de un diálogo que logra procesos inclusivos, donde la participación juega un lugar imprescindible. Una participación que respeta las voces de los excluidos porque sin este requisito no hay comunicación y menos puede hablarse de estrategias de "desarrollo humano". En Calandria, como narra Rosa María Alfaro (2006), se dieron cuenta de la riqueza de las capacidades comunicativas y el desarrollo cultural de sectores excluidos por la sociedad y de que "era posible alterar las relaciones de subordinación y crear otras de liberación" (Alfaro, 2006: 5).

to, a través de lo fragmentario y cotidiano (...) Pero desde antiguo se supo que, frente a la "Gran Historia", las pequeñas historias desenmascaraban su mentira y resultaban subversivas (...) ésta es siempre la estética del relato: la de lo pequeño y fragmentario, lo particular y cotidiano, lo visto y lo oído, pero que nos concierne a todos porque es hermoso o terrible; en modo alguno ajeno al conocimiento y a la verdad, entonces". 
Otra característica clara de la comunicación para el desarrollo es su disidencia con las diferencias, con esas pequeñas construcciones que trata de alejarnos a los seres humanos. Diferencias entendidas como asimetrías, grietas, brechas y abismos. Implica también referirse a procesos con voluntad de cambio y transformación. Procesos que son conscientes y articulan acciones con un objetivo común; su aparente fragmentación contrarresta un escenario global lleno de falacias y riesgos homogeneizadores. Son estrategias contrarias a toda forma de poder concentrado, es decir, a toda forma de "falsa comunicación-monólogo", que diría Mario Kaplún (1998: 64).

Pasemos ahora a aproximarnos a cada término por separado - comunicación y desarrollo humano- , tratando de no olvidar los consabidos abusos, para después retomar el término en su conjunto y revisar la cercanía a otros conceptos citados. Nuestra voluntad, más que enfrentar conceptos, traza puentes que articulan espacios transformadores ya sea desde el ámbito de la cooperación para el desarrollo como desde el de movimientos populares o comunitarios.

\subsection{COMUNICACIÓN}

Partamos de su etimología, de su raíz latina, communis, que significa poner en común algo con otro. Como señala Mario Kaplún, "expresa algo que se comparte: que se tiene o se vive en común" (Kaplún, 1998: 60). Es decir, lo compartido marca los límites y excluye a otras consideraciones de flujos unidireccionales. La comunicación, por tanto, es un proceso de intercambio, que busca consensos inclusivos, pero también el respeto a las diferencias. Ello permite amortiguar los desencuentros, y facilita la convivencia de los disensos, en un espacio donde todos deberían ser tenidos en cuenta por los otros. Está relacionada con el ser ampliado de Hannah Arendt, ese individuo capaz de entender lo que siente y piensa otro conciudadano ante lo público. Es el cauce que utiliza el pensador para contemplar los hechos teniendo en cuenta las percepciones e ideas de los conciudadanos (lo contrario a la doxa u opinión individual antes aludida). La capacidad de juicio del individuo está conectada a la habilidad para ver las cosas no sólo desde el punto de vista personal sino también según la perspectiva de todos los que estén presentes (Roiz: 2002; 6).

Comunicación, como nos recuerdan Burgui y Erro, tiene más de juego y relación humana que de estrategia, y es clave en todos los procesos de intervención y transformación social $(2010 ; 5-8)$. Es necesario reconocer la densidad comunicativa de lo social y superar la colonización de la acción social por la racionalidad económica, recuperando discursos inmateriales y comunicativos (García Roca: 2010).

Los teóricos latinoamericanos, como nos recuerda Luis Ramiro Beltrán (2007: 284), pusieron ya en cuestión los modelos como el de Harold Lasswell (1948), precisamente por su falta de puesta en común de ese algo:

Se halló que el de Osgood enfatizaba como objeto de la comunicación el ejercer influencia sobre la conducta del prójimo por medio de la persuasión; que el de Berelson evidentemente percibía la comunicación como transmisión; que el de Schramm — parcialmente inspirado en la teoría matemática de la comunicación for- 
mulada por los ingenieros Shannon y Weaver - resultaba mecanicista, y que el reformulado posteriormente por Schramm con Berlo - el harto conocido modelo FuenteMensaje-Canal-Receptor-Efecto- venía a ser la versión más desarrollada y vigente del paradigma clásico" (Beltrán, 2007: 284).

Una de las objeciones a este modelo era su esquema autoritario, y alejado de una visión que profundizara en una sociedad democrática. Al fin y al cabo diálogo significa etimológicamente "dos logos comunicándose". Por tanto, estas críticas se realizaban desde una concepción de la comunicación como proceso de significados y redefiniciones flexibles, con espacio para la convivencia entre formas dispares de ver el mundo, que aceptaran el reto de vivir con otras personas diferentes.

En un mundo con cascadas de riesgos homogeneizadores (por ejemplo, la mayoría de las salas multicines, debido al oligopolio de la distribución, proyectan desde la misma voz una única visión de la historia y del mundo), la comunicación - también como mediadora de la cultura - es el camino para conocer y reconocer la diversidad que, como señalaba Tulio Hernández, "es proceso de valoración del otro"5. Aprendemos y crecemos al descubrir lo nuevo que nos proporciona reconocer al otro mientras el otro nos reconoce a nosotros. Hay que desarmarse de una perspectiva para armarse del otro. La alteridad - la condición de ser otro en un sentido metafórico- es parte de la comunicación.

Comunicación, en su reivindicación humana, puede que sea una atalaya desde la que mirar el horizonte, pero también es "la otra brújula interpelante" de la que nos habla Alfaro (2006) que, sin duda, nos ayuda a reconocernos como miembros de una misma especie. Sí, es cierto que la comunicación está en la médula del desarrollo, pero si optamos por una visión más comprehensiva (que no es nueva, pero que se instala sobre oleadas de malentendidos e intenciones espurias), también diremos que el desarrollo - ese que incluye y construye desde una perspectiva equitativa y de respeto a las diversidad - es consecuencia de la comunicación, de esa puesta en común, del proyecto transformador.

Para marcar el espacio epistemológico de la comunicación parece útil seguir la ruta que marca los intentos por conceptualizar el derecho a la comunicación. Entre los esfuerzos realizados por recopilar las distintas dimensiones o capas que éste comprende, nos parece interesante destacar cómo L.S. Harms (2002) sistematiza las propuestas hechas y las sintetiza en tres niveles.

El primero, el concepto fundamental, englobaría un derecho necesario e indispensable para la convivencia social. Como señala Wayls Becerril (2009) "brinda la posibilidad de que todas las personas puedan comunicarse en todos los espacios de su vida". Se desprenden de aquí cuestiones que tienen que ver con la libertad de expresarse, pero también con la existencia de un clima que fomente el uso de las palabras propias, el respeto a los demás, la voluntad de convivir con los diferentes, el libre desarrollo de las identidades y el hacer valer puntos de vista distintos en relaciones de igualdad.

5 En el Seminario Internacional "Las relaciones entre comunicación y cultura para el desarrollo. Un compromiso con los Objetivos de Desarrollo del Milenio”, octubre 2011, Universitat de Girona. 
Para todos estos usos de la comunicación para la convivencia, ha jugado a favor el desarrollo de las tecnologías de la información, pero en cambio se ha renunciado a poner en valor el tiempo que es necesario para el desarrollo del diálogo en la plaza pública. Se ha restado importancia en aras de la "eficiencia", de la inmediatez. Recuperar tiempo para relacionarnos y dialogar, refundar los espacios públicos donde se establece el contacto y recuperar la palabra y la comunicación, entonces (lo que implica incluso mejor planificación urbanística), se hace imprescindible para comenzar a hablar de comunicación para el desarrollo, o de una ciudad - ágoraeducadora.

El segundo nivel señalado por Harms es el inclusivo, que se liga a aquellos derechos (de reunión, discusión, participación; el derecho de inquirir, de estar informado, de informar; o los derechos a la cultura, a la elección, a la intimidad...) que permitirían alcanzar el disfrute del derecho humano a comunicar. Todos ellos ya se ponían en valor en el informe MacBride (1980). Siempre que nombramos este informe constatamos la renuncia a un Nuevo Orden Mundial de la Información y de la Comunicación, es decir, a un sistema donde primara el intercambio equitativo y la reciprocidad. Roberto Savio (2011), testigo y uno de los protagonistas del momento desde la Agencia IPS, señala la importancia de contextualizar el debate sobre la información en la historia de la postguerra para entender cómo se ha llegado al actual "Orden Mundial de la Información del Mercado, que los jóvenes creen que es el estado natural de las cosas".

Y no es un tema menor, porque comunicar el desarrollo humano también es abordar el patrón de ganadores y perdedores de la Sociedad de la Información. El terreno fue ocupado por un discurso dominante que ahoga rápidamente las resistencias. A los perdedores, es decir, a todos los ciudadanos del mundo que se nos arrebató la oportunidad de disponer de un sistema de información y comunicación menos concentrado e independiente del poder económico, nos toca ejercitar la memoria colectiva. "Lo malo de ser pobre es que te pasas la vida escuchando", dicen que le espetó un payés al periodista y escritor Josep Plá6. Solo los ganadores -es decir, los países que han ostentado la hegemonía y los grandes conglomerados multimedia - prefieren olvidar, hacer que se olvide, porque resucitar la agenda MacBride sería abrir espacios a formas de poder compartidos y dar altavoz a voces que han permanecido silenciadas.

La última dimensión que señala Harms es la integral. Como apunta Becerril (2009), aquí se ubican las propuestas que han intentado definir al derecho humano a comunicar como ese gran marco general que da cabida tanto al entendimiento de este derecho como principio guiador de la vida social, como aquellos derechos particulares que pueden ser incorporados o que podrían surgir con el tiempo. Se preguntaba Cees J. Hamelink (2002) cómo íbamos a diseñar las futuras "sociedades de la comunicación". Y escribe, "por extraño que parezca, la Conferencia Mundial de la ONU sobre Derechos Humanos (Viena, 1993) no se refirió a la comunicación en su Declaración Final. Sólo había una mención de información y noticias. Dicha omisión esencial no debe ser repetida en la Declaración Final de la Cumbre Mundial

6 Citado por Manuel Vicent en una tribuna de El País (16 de enero de 2000). 
sobre la Sociedad de la Información". Pero, lo fue. Omitida. Por otra parte, la UNESCO fue la única de las agencias de la Naciones Unidas que incluyó, por expreso deseo del responsable del departamento de Filosofía, Paul Ricoeur, el topoi comunicación. En los setenta. Nunca más. Hamelink agrupa los elementos clave que vertebran una Declaración Universal sobre el Derecho a Comunicarse, esto es los derechos de información, los derechos culturales, los derechos de protección, los derechos colectivos, los derechos de participación.

En todo este panorama, la existencia de nuevos desarrollos tecnológicos que han dado lugar a lo que ha tomado distintas etiquetas -la Sociedad Red (Castells), Sociedad Tecnocientífica (Virilio) o Sociedad Tecnológica Avanzada (Negroponte)no cambia la esencia de esta conceptualización de comunicación. El uso de Internet y de las redes sociales, a pesar de los ruidos y de los riesgos manipuladores, vendría a facilitar las dimensiones repasadas, a multiplicar las posibilidades para la puesta en práctica de este derecho.

En conclusión, la comunicación operaría como un holón teórico - cuya propiedad es establecer vínculos - si quieren, una luz inspiradora, pero también una herramienta tangible que nos ayuda a irrumpir en distintos escenarios y operar sobre ellos haciendo interteoricidad. Como agrupador de elementos teóricos procedentes de distintas disciplinas científicas.

\subsection{DESARROLLO HUMANO}

El concepto de desarrollo, si bien está tejido por hilos contextuales que acaban fácilmente enredando sus significados, también contiene la posibilidad de una definición epistemológica que delinee o demarque sus contornos humanos. Indagamos pues en un "desarrollo humano", confluyente después con la visión defendida sobre la "comunicación", que recupera espacios y se libra de las ocupaciones. Nuestra intención es la de posicionarnos, y somos conscientes de que es imposible en este espacio realizar un análisis exhaustivo del término.

Amartya Sen (2000) conceptualizó el Desarrollo Humano en la década de los ochenta. Más que un fin en sí mismo, Sen definió el desarrollo como un medio para lograr una mayor calidad de vida, e incluso la felicidad, relacionándolo con los procesos que amplían las opciones y oportunidades de las personas. En el centro de sus teorías está el concepto de libertad que describe como participación en la economía o en la política, pero también como la obtención de oportunidades sociales (derecho a exigir educación y servicios sanitarios, existencia de mecanismos de protección social como el seguro de desempleo o subsidios en caso de que se necesiten). Carecer de alguna de estas dimensiones implica ausencia de desarrollo.

$\mathrm{Su}$ aproximación al concepto de capacidad es enfocado desde la libertad positiva, que es la capacidad real de una persona de ser o de hacer algo, es decir, por ejemplo, no es suficiente con tener un mercado cerca si las personas que están alrededor carecen de la capacidad para comprar y tampoco bastaría con la existencia de unas urnas para votar si los potenciales votantes no cuentan con los medios para llegar hasta el lugar donde ejercer su derecho al voto. 
Vemos pues que cuando hablamos de desarrollo no nos referirnos al fracaso de las recomendaciones hechas por las instituciones Breton Woods (FMI, BM...) ni a los descalabros de algunos tipos de ayuda orientados a crear más relaciones de subordinación y dependencia. Tampoco de un concepto enfrentado a la noción de "Tercer Mundo" (inventada por los franceses en los años cincuenta) ni a la de "países subdesarrollados" (utilizada por Truman en 1949). Nos ceñimos más bien a un proyecto de sociedad, a un proceso de intercambio - de ahí su inevitable unión al término comunicación - donde las experiencias son compartidas así como los aprendizajes, pero que además incide en la vida de los ciudadanos incluyéndolos desde un reconocimiento real de sus derechos y de su protección.

Aunque escrita hace décadas, la obra de Gilbert Rist, El desarrollo: una creencia occidental, aborda desde una perspectiva crítica, el concepto de desarrollo, y lo sitúa en el ámbito de las creencias sociales (2002: 33), como una idea destinada a lograr adhesiones unánimes, con gran capacidad de seducción, y por eso, pese a sus fracasos — dice - nadie pone en cuestión su legitimidad (Rist, 2002: 13). Para el autor suizo el desarrollo es "la expresión del deseo... de vivir una vida mejor, pero que parece ignorar voluntariamente las dificultades para su realización" (Rist, 2002: 22-23).

El "desarrollo" está constituido por un conjunto de prácticas a veces aparentemente contradictorias que, para asegurar la reproducción social obligan a transformar y a destruir, de forma generalizada, el medio natural y las relaciones sociales a la vista de una producción creciente de mercancías (bienes y servicios) destinadas, a través del intercambio, a la demanda solvente (Ib.,: 24-29).

Desde la II Guerra Mundial, el desarrollo como ideología o creencia fluctuó entre visiones particulares apegadas al pasado y formulaciones del futuro a escala global. Las distintas maneras de concebir el desarrollo surgidas, las incoherencias del inicio de la arquitectura de ayuda internacional — que también sufrirá el contexto de guerra fría - se fue enredando con visones que dejaban atrás aquella centrada en el crecimiento económico, para dar luz entre los años ochenta y noventa a una concepción del desarrollo que miraba más a la equidad y la reducción de las desigualdades sin olvidarse de la necesidad de reducir los impactos que sobre la naturaleza produce la acción humana, como así hiciera el Informe Brundtland sobre Desarrollo Humano Sostenible (1987).

De todas maneras, los distintos actores, discursos, acciones e interacciones que se aparecen de forma sincrónica o diacrónica configuran un campo complejo, donde al mismo tiempo, y enredadas en relaciones de poder, perviven visiones y posiciones políticas que van desde el crecimiento económico y la acumulación del capital sin límites hasta el objetivo de una sociedad más equitativa y de una gobernanza global donde primen las relaciones de cooperación justas. Una visión, esta última, donde aparece un enfoque internacionalista y una superación de ese desarrollo traducido en la superabundancia de consumo para unos cuantos al lado de la exclusión y la pobreza de la mayoría.

Esta simultaneidad de ámbitos llevó a que las incertidumbres y contradicciones que giran en torno a un mundo globalizado, como señala Alfaro, continuaran, incluso cuando ganaron protagonismo ámbitos más locales y centrados en grupos humanos micro territorializados en actores de una misma identidad (género, racial, étnico 
cultural, etc.) en detrimento de los marcos del Estado-nación y se avanzó en una concepción del desarrollo más centrada en la persona y en la convivencia sobre la base de códigos que garantizasen derechos e igualdad ${ }^{7}$.

Y, sin duda, la pieza clave fue ligar el desarrollo desde una perspectiva de derechos, ya que sólo una aplicación efectiva de los derechos humanos a escala universal puede evitar las aberraciones del totalitarismo político y del totalitarismo del mercado, en particular, del mercado financiero. Así se manifestaba la jurista Mireille Delmas-Marty. Observar el derecho como una dinámica de humanización de las prácticas del ser humano va al encuentro del desempeño de su verdadero papel.

Pero sólo, si resiste a la deshumanización, responsabiliza a los depositarios de un poder global y prevé los riesgos verdaderos tomando como referencia los componentes comunes de la humanidad. Por ejemplo, la singularidad de cada ser humano y su pertenencia a la comunidad humana en pie de igualdad. Los peligros que entrañan las nuevas tecnologías, inducen a añadir a esos dos componentes el de la indeterminación. La parte de libertad y el fundamento de la responsabilidad del ser humano estriban en el hecho de que éste no está determinado de antemano (Delmas- Marty,2011: 32).

El desarrollo al que nos referimos, aunque entrañe una paradoja, tiene que ver con muchas de las objeciones que las teorías de desarrollo crítico hacen a ese otro y manido "desarrollo" apegado a los efectos negativos del capitalismo, la industrialización o la degradación medioambiental. Por ejemplo, con las teorías del decrecimiento o del postdesarrollo, así como el ecofeminismo (Shiva: 2007) y desde los estudios postcoloniales (Mignolo y Escobar).

La crisis medioambiental o ecológica hace que no baste con hablar de como repartir mejor los frutos del industrialismo, sino que también hay que afrontar el cambio de modelo de consumo educando nuestra capacidad de austeridad en el norte y encontrar una nueva relación de equilibrio con la naturaleza. Además, el incremento de la desigualdad en los países ricos (OCDE: 2011), la nueva dominación de las corporaciones y las enormes inequidades en las relaciones de género todavía dejan al desarrollo en un terreno de posibilidades a futuro, porque ya no vale la máxima de países desarrollados cuando son "subdesarrollados" en patrones de consumo y problemas medioambientales. El desarrollo todavía es ese camino que hay que construir mirando a la utopía, para avanzar en ese deseo de vivir una vida mejor.

Aldous Huxley, desde la conciencia anticipatoria que brinda la literatura, dibujó en su obra póstuma, La isla (1963), una sociedad que persigue el "buen vivir"8. Merece la pena adentrarse en la ficción para analizar lo que podría ser una práctica de un modelo de desarrollo (no perfecto, pero al menos deseable) donde no entran

7 En Latinoamérica, señala Alfaro, las acepciones del desarrollo casi siempre estuvieron asociadas más a políticas que se tradujeron en prácticas económicas, sociales, políticas y culturales de intervención que a teorías (2006:23-24).

8 En quechua "Sumak Kawsay", según Walter Mignolo, exige una alternativa al desarrollo y se distingue del American Way of Life, que significa vivir mejor a costa de que otros vivan peor. La paradoja queda servida porque muchos autores latinoamericanos prefieren este concepto del "buen vivir" al referirse a algo muy parecido a lo que venimos definiendo como desarrollo. 
en conflicto el ejercicio de la libertad, la preocupación por una educación comprehensiva, el uso sostenible de los recursos, la equidad, la participación, la comunicación dialógica, etc.

Ésta sería la última conceptualización del desarrollo, la del buen vivir. Por ejemplo, Alberto Acosta y Esperanza Martínez (2009) dicen que este término alude a una propuesta alternativa a la lógica del desarrollo que subyace al neoliberalismo imperante y a quienes apuestan por la existencia de mercados autorregulados y la privatización de los servicios públicos. También está ligado al cuidado del medioambiente, al despliegue de la solidaridad y a la profundización de la democracia. Esta visión casa a la perfección con el concepto de "desarrollo" que estamos definiendo y que forma parte de la comunicación para el desarrollo, para la transformación social.

\section{COMUNICACIÓN PARA LA TRANSFORMACIÓN SOCIAL. CIUDADANÍA, DERECHOS Y POLÍTICA DE FINES}

La comunicación funciona como esa "nueva brújula" que describe Alfaro (2006: 3), "que nos orienta para gestar vínculos entre los más diversos fragmentos que existen en nuestra sociedad (...) conquistando sociedades más articuladas entre sí", e involucra a los sujetos en la gestión de su propio desarrollo. Es decir, conecta la movilización comunitaria y abre la posibilidad de construcción de diálogos y saberes, de aprendizajes comunicativos, de tejidos sociales comunicantes.

Pero además la comunicación puede ser un factor de visibilización de la pobreza y de legitimación del desarrollo, una fuerza simbólica y moral que recoloca los derechos en la calidad de vida como eje de nuestro accionar, para ser legitimados por todos (Ib.,: 34).

La definición que hace Alfonso Gumucio Dagron (2004: 5-6) de la comunicación para el cambio social nos parece muy cercana a lo que intentamos definir aquí como comunicación para el desarrollo: "Una comunicación ética, es decir, de la identidad y de la afirmación de valores; amplifica las voces ocultas o negadas, y busca potenciar su presencia en la esfera pública. Recupera el diálogo y la participación como ejes centrales.

Sin embargo Gumucio diferencia este tipo de comunicación participativa de la que califica de instrumental, vinculada a los programas de desarrollo, que a su juicio realizan las grandes agencias de cooperación internacional (FAO, UNESCO y UNICEF, entre otras). Según el autor (2004: 5), este tipo de comunicación reconoce la importancia del saber local, de la tradición y de la cultura, aunque no logra trasladar el centro de gravedad de las decisiones y procura promover cambios de comportamiento a través de roles modelo y de técnicas de entretenimiento.

Sin duda, este planteamiento puede servir de invitación al sistema de cooperación para el desarrollo para que avance en su reflexión sobre el rol de la comunicación. Que se empiece a pensar en ella, "no como aquella que se adjunta al desarrollo dándole eficacia", sino como la que "gesta impulsos y caminos de cambio que humani- 
zan y vuelven atrevida la intervención" (Alfaro, 2006: 9). Si se entendiera su potencial, más allá de la difusión de información y del uso del marketing, la comunicación facilitaría "el espacio de diálogo" que necesita la cooperación para el desarrollo para fortalecerse como instrumento de equidad y justicia social. Aunque esta recomendación también puede extenderse a los ámbitos del resto de las políticas públicas y del cuidado del bien común y la lucha contra las inequidades.

Y todo empieza por buscar ese lugar donde las culturas dialoguen y la ciudadanía, desde la responsabilidad, participe. "Es a partir de esta construcción común, no impuesta desde arriba, sino tejida desde lo cotidiano, que es posible plantearse cambios profundos", señala Kaplún (2007: 314). Eso no significa renunciar a los medios, los mensajes y las campañas, "pero sí poner el acento en los procesos de comunicación en los que se construyen y reconstruyen colectivamente vínculos y sentidos" (Ibid.; 314).

Quizás por su tradicional distanciamiento de esta visión en el mundo de la cooperación, Kaplún (2007: 314) distingue la comunicación para el desarrollo de otras como la popular, educativa o comunitaria. Desde una perspectiva crítica señala, recordando a Paulo Freire y a Arturo Escobar, que aquella intenta imponer verdades y procederes externos en vez de un diálogo de saberes, o la imitación acrítica de un camino de los países desarrollados no necesariamente deseable para las periferias del mundo globalizado. Estas opiniones deberían dar origen a reflexiones, o complementar las que ya se están llevando a cabo, en el marco de la agenda para la eficacia de la ayuda 9 .

Otra falacia en la que parece se sigue cayendo dentro del sistema de cooperación internacional para el desarrollo y también desde otras políticas públicas con intención transformadora es el sobredimensionar el papel de los medios de comunicación ${ }^{10}$. Se desperdician muchos esfuerzos y recursos orientados al mainstream, cuando en general ayudan muy poco al desarrollo y al cambio social. Contaba Germán Rey ${ }^{11}$ que un amigo le dijo: "El mundo se le escapó al periodismo, ahora lo que tenemos que hacer es reinventarlo". El periodismo que reflejasen los medios de comunicación puestos al servicio del poder económico o político, como ya apuntan muchos profesionales desde dentro, se ha vaciado de principios éticos y compromisos colectivos.

En el último Foro Social Mundial, Chico Whitaker ${ }^{12}$ proponía dejar de angustiarnos con la dificultad de romper el bloqueo de los grandes medios de comunicación de masas ${ }^{13}$, así como la de no poder satisfacerse con medios de comunicación

9 http://www.oecd.org/document/12/0,3746,en_2649 3236398_46057868_1_1_1_1,00.html.

10 Ver MurCiano, Marcial et al. (2009), La prensa y la cooperación para el desarrollo, Aecid-IPS-UIMP, Comunicación Social.

11 En el Seminario Internacional "Las relaciones entre comunicación y cultura para el desarrollo. Un compromiso con los Objetivos de Desarrollo del Milenio", octubre 2011, Universitat de Girona.

12 "Chico" Whitaker ¿Nuevas perspectivas en el proceso del FSM?

http://www.fsmmadrid.org/web2/index.php/noticias-del-mundo/54-noticias-del-mundo/498-m-inuevasperspectivas-en-el-proceso-del-fsm-por-francisco-qchicoq-whitaker

13 Aludiendo a la invasión que se hace de algunos términos, Mario Kaplún (1998: 60) recuerda el origen del término "medios de comunicación". Los norteamericanos los denominaron simplemente mass media, medios masivos o de masas, pero después se apropiaron del término "comunicación". "Así, en lugar de partir de las relaciones humanas, fueron la técnica, la ingeniería, la electrónica -y las poderosas empresas propietarias de los medios- los que impulsaron la forma de concebir la comunicación” (Kaplún, 1998). 
alternativos. Su propuesta consistía en empezar a usar de manera mucho más sistemática las herramientas para la intercomunicación horizontal libre, así como otros medios como el cine, la radio, el teatro, la música, la pintura o las publicaciones. Pero más allá de las grietas por donde se filtran algunas manifestaciones libres, ¿no padecen también todos ellos los límites impuestos por el mercado o la dejadez del poder político por hacer valer las políticas culturales adecuadas? ${ }^{14}$.

Sin embargo, sirva si acaso como ayuda-memoria, anotemos que la proposición derechos de participación, elemento clave para una Declaración Universal sobre el Derecho a Comunicarse (Hamelink, 2002) acoge los derechos a adquirir las capacidades necesarias para participar plenamente en la comunicación pública; el derecho de la gente a participar en la toma de decisiones sobre la provisión de información, la producción de cultura o la producción y aplicación del conocimiento; el de participar en la toma de decisiones públicas en la elección, desarrollo y aplicación de tecnologías de la comunicación. Apunta, desde luego, más alto que la intervención que pueda hacer la ciudadanía con instrumentos como los Pactos por la ciudadanía ${ }^{15}$ o acuerdos entre actores sociales y políticos sobre un determinado orden social. Y traza una interesante y definitiva línea divisoria entre negociación y deliberación.

Nos particularizan nuestras carencias del mismo modo que nos agrupan. El realineamiento de la economía mundial si bien habría incidido en una reducción de la pobreza en términos absolutos también habría intervenido en el aumento de la desigualdad en el interior de los países. "Mientras, las transformaciones han sido de mayor calado que el inicialmente previsto, las políticas de reforma y de distribución en los países de la OCDE no han sido a menudo suficientes para compasar los desafíos de la globalización y la desigualdad y debilitamiento social han aumentado" (De La Rocha, 2011). Construir sociedades inclusivas y cohesionadas deberá ser el más importante de los retos que tengamos que afrontar las próximas décadas. Nos exigirá un cambio de mentalidades preciso: transformar un sistema de relaciones político-económico-tecnológico-educativo basado en la acumulación (de representatividad, de beneficios, de mercados, de conocimientos) en otro, que sea suma de las capacidades y de los intercambios o la cooperación (no tan sólo de voluntades cuanto también de fines) para crecer en oportunidades individuales y colectivas. El actual patrón ganadores-perdedores tiene recambio si el fin último de nuestras intervenciones sociales, esto es, la competitividad se sustituye por el de la cooperación. De hecho, seguramente se está haciendo en comunidades y ámbitos locales. O se ha venido haciendo ya. La creación de capacidades queda vehiculada al principio fundamental de la alfabetización y el acceso universal y gratuito a la educación. Y debe incluir la formación necesaria para utilizar las tecnologías de la información y la

\footnotetext{
14 Se sigue echando en falta políticas públicas que liguen la comunicación, la cultura y la educación. Las primeras se dejaron en manos del mercado, la segundas de cuestionables usos políticos.

15 Como queda referido en el estudio Una nueva politica de cooperación para el desarrollo de la Unión Europea con América Latina (por encargo del Parlamento Europeo, 2011): "En general, este tipo de pactos son de difícil implementación, pues suelen carecer de mecanismos para su institucionalización, pero desempeñan un rol fundamental para fijar expectativas y perspectivas temporales para que los acuerdos cristalicen más adelante en políticas públicas concretas". (Disponible en wwww.europarl.europa.eu/activities/committes/studies.do?language $=\mathrm{EN})$.
} 
comunicación así como para establecerse críticamente ante los medios masivos y la información. Entre las habilidades necesarias de una ciudadanía activa encontramos esencial la de construir aprendizajes significativos donde la capacidad crítica de búsqueda, selección, diseño, creación y utilización de información y tecnologías están en el inicio de su autonomía. Proponer, pues, la apropiación social de las tecnologías exige garantizar el acceso universal a la información fundamental para el desarrollo humano. Si dejamos que información y conocimiento sean cada vez más recursos cada vez más privados que puedan ser controlados, vendidos, comprados como mercancía es que hemos olvidado su lugar fundamental en la construcciónconstitución individual y colectiva. En la Declaración de la Sociedad Civil en la Cumbre Mundial sobre la Sociedad de la Información - CSMI, 2003-2005- 8 de diciembre de 2003, leíamos:

La desigual distribución de las TIC y la falta de acceso a la información que tiene una gran parte de la población mundial, fenómenos que suelen denominarse brecha digital, son de hecho una expresión de nuevas asimetrías en el conjunto de brechas sociales existentes. Éstas incluyen las brechas entre el Norte y el Sur, los ricos y los pobres, los hombres y las mujeres, las poblaciones urbanas y rurales, aquellos que tienen acceso a la información, aquellos que carecen del mismo. Dichas disparidades pueden verse no sólo entre las diferentes culturas, sino también dentro de las fronteras nacionales. La comunidad internacional debe ejercer su poder colectivo para garantizar que los Estados adopten medidas con el fin de reducir las brechas digitales nacionales.

Las tensiones entre un modelo tecnológico transferente, que perpetúa las tendencias negativas de la globalización económica y el monopolio cognitivo, y otro modelo que trata de explorar aperturas educomunicacionales para atender las necesidades humanas y contribuir a transformar el paradigma del desarrollo del primero, traducen el momento actual, en construcción, de las sociedades de la comunicación. La Sociedad Civil de la CMSI, entendió que compartir de modo universal las tecnologías, la información y el conocimiento exigía entonces como ahora el refuerzo del marco reglamentario y jurídico en todas las sociedades de la información y de la comunicación así como empoderar a las comunidades respetando los derechos y las libertades humanas. De este modo, subrayando el enfoque de derechos, destacaba el papel que el Estado debía asumir en la construcción de política pública de largo plazo para que los beneficios del desarrollo llegasen a todos los sectores de la población y revertir los desequilibrios de poder.

Transformar las actuales sociedades en sociedades de la comunicación nos obliga a detener la mirada ante el horizonte de referencia constituido por la cohesión social como eje de la política de desarrollo "desde el cual pueden originarse opciones políticas diversas, de acuerdo con los diferentes contextos políticos, sociales, económicos y culturales ${ }^{16}$. La receta para el mal que aqueja a la economía global se deduce inmediatamente, ha señalado Joseph Stiglitz (2011) a partir de este diagnóstico:

16 En Una nueva politica de cooperación para el desarrollo de la Unión Europea con América Latina. (Disponible en www.europarl.europa.eu/activities/committees/studies.do?language=EN). El estudio, de 2011, ha sido solicitado por la Comisión de Desarrollo del Parlamento Europeo. Sus autores son Pedro 
Hacen falta sólidos programas de gasto público que apunten a facilitar la reestructuración, promover el ahorro energético y reducir la desigualdad; y junto con esto, una reforma del sistema financiero internacional que cree alternativas a la acumulación de reservas. Tarde o temprano los líderes mundiales (y los votantes que los eligen) se darán cuenta de que es así, ya que, conforme las perspectivas de crecimiento siguen empeorando, no les quedará otra alternativa. ¿Pero cuánto sufrimiento debemos soportar hasta que eso ocurra?

¿Puede articular la cohesión social un cambio significativo? Creemos que sí, sólo si sale al encuentro de la justicia. Creemos que no, si queda constreñida y concernida en tanto anclaje de las agendas políticas a un tiempo de contingencias. Y no, seguramente, sin finalidad y profundización en derechos humanos en ámbitos como el trabajo, la seguridad social, la educación, la cultura, el agua y el medio ambiente y los derechos vinculados con la autonomía, en tanto garantes de las condiciones materiales que hacen posible a cada persona el ejercicio real de sus libertades. Un núcleo de valores compartidos que fundamenta el encuentro deliberativo. Es inmediata entonces, la exigencia de habilitar espacios de participación ciudadana que acompañe en la proyección de políticas públicas, de las que los ciudadanos se sienten parte activa en el orden de los efectos. Pero no de las causas. Por eso, tal vez, se precisa de un procedimiento de escucha ciudadana, de comunicación (que lo es de acompañamiento en la deliberación pública que antecede a la toma de decisiones de los actores político-institucionales) y de corresponsabilidad de un espacio público inundado de informaciones razonadas que precisa adoptar decisiones sobre opciones vitales que puede ver afectadas.

En América Latina - leemos en el estudio Una nueva política de cooperación para el desarrollo de la Unión Europea con América Latina (2011: 59)_ " "la participación de la sociedad civil en el diseño de políticas para la incorporación de las demandas y prioridades de los colectivos excluidos de los procesos de desarrollo se ha convertido en una demanda generalizada de los actores sociales. Los crecientes espacios de participación existentes - en unas ocasiones como resultado de las reivindicaciones de la propia sociedad civil y en otras impulsados por una apertura gubernamental- están dando respuesta, en parte, a este objetivo. No obstante, es importante mejorar la calidad de los espacios de participación a través de una mayor vinculación de las decisiones adoptadas en ellos, de la superación de la instrumentalización de estos espacios y de un papel activo en la defensa de los intereses colectivos desde su interior".

Morazán, Antonio Sanahuja y Bruno Ayllón. Hacen referencia a la relectura que la CEPAL está realizando sobre el papel que desempeña la cohesión social en los procesos de desarrollo como un fin y como un medio. "Como fin, es objetivo de las políticas públicas que apuntan a que todos los miembros de la sociedad se sientan parte activa de ella, contribuyan al progreso y se beneficien del mismo. Pero la cohesión social también es un medio para pilotar el desarrollo desde una perspectiva de calidad democrática que contribuya a legitimar las instituciones, crear ciudadanía y enfrentar situaciones adversas en la vida de las personas. Para ambos propósitos, los actores sociales deben sentirse como partes de un todo y estar dispuestos a ceder en algunos de sus intereses personales en aras del beneficio del conjunto. Esto implica instrumentar acciones que permitan paliar la situación de los grupos más vulnerables a través de la adopción de políticas públicas de largo plazo que favorezcan la igualdad de oportunidades, la movilidad y el empoderamiento de los más excluidos" (Ver pp. 56-57 y 58). 
Se estima oportuno en este contexto plantearnos el tipo de profesional que necesita la comunicación para el desarrollo, ya que estamos, como señala Alfaro, "ante espacios profesionales y de acción que resultan de confluencia de acercamientos sociológicos, culturales, políticos y psicológicos entre otros" (2006: 13). Más que un experto en medios, estaríamos hablando de un facilitador de la comunicación, capaz de dinamizar espacios interpersonales, grupales, colectivos, desde la consulta médica a la asamblea barrial.

Capaz de pensar a las propias organizaciones sociales y a las instituciones como espacios de comunicación, cuyos diseños y funcionamiento pueden ayudar más o menos al diálogo, desde las estructuras de representación sindical a los presupuestos municipales participativos. Y también, claro, capaz de ayudar a las comunidades a apropiarse de los medios (Kaplún 2007; 314).

Por otro lado, la relación estrecha que tiene la comunicación para el desarrollo con otras dimensiones que tienen que ver con lo cultural o lo educacional tiene que ser tenida en cuenta. La cultura y la educación para el desarrollo comparten con la comunicación su objetivo transformador, un importante impacto en derechos humanos y un componente socializado basado en la convivencia desde lo diferente. Como Germán Rey ${ }^{17}$ describió la cultura es el modo que tenemos de imaginarnos y representarnos la convivencia. El gestor cultural, como el comunicador, es un gestor de disensos. Conceptos muy cercanos "educación cultural", "ciudadanía cultural", Educación para el desarrollo, educación para la ciudadanía, construyen espacios que luego los hombres habrán de hacer habitables en y para su relación con el mundo. Deben poner al alcance de nuestra mano las herramientas del reconocer -conocerse en el otro- y de la experiencia - una variable ilimitada del actuar sobre lo material e inmaterial- . No podemos construirnos solos social y culturalmente. Hace veinte años, el $20 \%$ de la población controlaba el $82{ }^{\prime} 7 \%$ del total de la renta global, en la actualidad ocupa el $91{ }^{\prime} 5 \%$. El 20\% más pobre del planeta tenía el 1'4\% de la renta, hoy posee el 0’007\%. “¿Por qué nos resulta tan difícil imaginar otro tipo de sociedad? ¿Qué nos impide concebir una forma distinta de organizarnos que nos beneficie mutuamente? ¿Estamos condenados a dar bandazos eternamente entre un "mercado libre" disfuncional y los tan publicitados horrores del "socialismo"? Nuestra incapacidad es discursiva, simplemente ya no sabemos cómo hablar de todo esto" (Judt, 2011: 45)

Hay, sin embargo, observadores y abordajes que solamente nos esperan. La universidad debe, y lo hace, recogerlos y exponerlos. Las referencias que utilizaremos a continuación son de autorías que incursionan desde ámbitos diferentes de las ciencias sociales en las transformaciones sociales y en la transformación de la mirada de quienes estamos obligados a darles sentido. A todas les agrupa, consideramos, la búsqueda de una divergencia o aplicarse en hallarla. Nos empistan hacia lugares sobre los que la comunicación podría detener su paso, al menos en el ánimo de operar sobre ellos.

\footnotetext{
17 En el Seminario Internacional "Las relaciones entre comunicación y cultura para el desarrollo. Un compromiso con los Objetivos de Desarrollo del Milenio", octubre 2011, Universitat de Girona.
} 
Citamos, hace unas páginas, a Mattelart para dar a conocer el lugar central que la ciudadanía activa ocupaba en la búsqueda de un nuevo contrato social, donde habría de residir el sentido de un trabajo de transformación. El objetivo ahora, escribía Edgard Morin en el diario El País de 17 de enero de 2010, es salvar a la humanidad. Para ello, entiende, urge cambiar nuestros modos de pensar y de vivir. La idea de la metamorfosis, plantea Morin, aporta la esperanza de un mundo mejor. “¿Cómo cambiar de vía para ir a la metamorfosis? Aunque parece posible corregir ciertos males, es imposible frenar la oleada técnico-científico-económica civilizatoria que conduce al planeta al desastre. Y, sin embargo, la historia humana ha cambiado de vía a menudo. Todo comienza siempre con una innovación, un nuevo mensaje rupturista, marginal, modesto, a menudo invisible para sus contemporáneos". La idea que subyace en su intervención es que, efectivamente, la metamorfosis sería un nuevo origen, de hecho todo ha recomenzado. "Estamos en los comienzos modestos, invisibles, marginales, dispersos. Pues ya existe, en todos los continentes, una efervescencia creativa, una multitud de iniciativas locales, en el sentido de la regeneración económica, social, política, cognitiva, educativa, étnica o de la reforma de vida". Estas iniciativas, sin embargo, "no se conocen unas a otras, ninguna Administración las enumera, ningún partido se da por enterado. Pero son el vivero del futuro". Se trata de reconocerlas, de censarlas, de compararlas, de catalogarlas, de conjugarlas en una pluralidad de caminos reformadores, dice Morin. Merecería la pena, hacer este esfuerzo de detección y narración de buenas prácticas comunicativas en los procesos de transformación social.

"Hay una falta de visibilidad general. Acontecimientos imprevisibles irrumpen con fuerza sin que nadie o casi nadie, los vea venir. Si gobernar es prever, vivimos una evidente crisis de gobernanza", escribía Ignacio Ramonet a comienzos del mes de octubre de 2011, cuando se acababan de cumplir diez años desde los atentados del 11-S y tres desde la quiebra de Lehman Brothers. Y se preguntaba por las características del nuevo sistema-mundo: “ Son los seísmos. Seísmos climáticos, seísmos financieros y bursátiles, seísmos energéticos y alimentarios, seísmos comunicacionales y tecnológicos, seísmos sociales, seísmos geopolíticos (...) El curso de la globalización parece como suspendido. Se habla cada vez más de desglobalización, de decrecimiento... El péndulo había ido demasiado lejos en la dirección neoliberal y ahora podría ir en la dirección contraria. Ya no es tabú hablar de proteccionismo para limitar los excesos del libre comercio, y poner fin a las deslocalizaciones y a la desindustrialización de los Estados desarrollados. Ha llegado la hora de reinventar la política y de reencontrar el mundo" 18 . Llegada la hora, nos interesa especialmente conocer las condiciones de posibilidad de la comunicación en el nuevo sistemamundo en el que indaga Ramonet. ¿Inaugura un tiempo nuevo para la comunicación? ¿Con quiénes? ¿Para cuántos? ¿Hacia dónde va este tiempo inaugural de la comunicación?

Desde la comprensión del cambiante contexto económico y político del orden mundial, David Held (2005: 15-21) trata de establecer una agenda de cambio global

18 En www.other-news.info/noticias[fecha de entrada: 7/10/2011] 
"sensata y factible" y propone un programa de acción que de respuesta a los problemas globales, que detecta y examina sobre la economía, la política y la legislación y sus impactos en la estructura del orden global. Si se trata de señalar las opciones disponibles, Held opta por un "amplio aunque práctico" programa de reformas políticas, sociales y económicas: "un nuevo pacto global para nuestra época también global", que constituiría la base de un orden democrático multilateral, asentado en normas y orientado hacia la justicia". Su enunciación sobre la pertinencia y el grado indispensables de determinado conjunto de valores socialdemócratas, está entre las opciones convincentes de las que disponemos como alternativa al consenso de Washington. El trabajo de Held lo es básicamente de mostración, de cómo pueden regularse los procesos globales con la finalidad de generar desarrollo humano, cambios económicos equitativos, democracia y mejor calidad democrática y justicia.

Habermas (2009: 90-95-96 y 101) detecta cinco problemas globales de la más alta prioridad. Vamos a detenernos en el marco institucional y la forma de gobernar que, según él, precisarán. Los problemas son la seguridad internacional, las previsiones globales "ante el colapso de los contrapesos ecológicos fundamentales para la vida (cambio climático, abastecimiento de agua potable, etc.)"; la distribución de recursos energéticos escasos, la imposición global de los derechos fundamentales del hombre; un buen orden económico mundial, "que (más allá de un ayuda ad hoc en casos de catástrofes en zonas miserables) supere las caídas extremas del bienestar y la distribución desigual de posibilidades de vida (cf. los Objetivos del Desarrollo del Milenio de la ONU)". Salvo el cambio climático que, en opinión de Habermas, podría tener alguna perspectiva de solución por la vía clásica de los tratados internacionales —en parte, por la naturaleza física del problema y, en parte, por el carácter inclusivo e inevitable de sus consecuencias - el resto de los problemas enumerados, en cambio, "no me puedo imaginar cómo podrían solucionarse sin una profunda reforma de la organización de las Naciones Unidas o el establecimiento de una política institucionalizada que abarque a todo el mundo (...)”. Una forma de gobernar que trasciende las fronteras nacionales. Empezar a construir un nuevo orden mundial "nos obliga a repensar otra forma de gobernar supranacional". Carecemos de un sistema de negociación representativo y transnacional, "que disponga de competencias suficientemente generales, es decir, que pueda dirigir su mirada al todo". Pero, nos avisa, "sólo formas de gobierno extendidas regionalmente y al mismo tiempo representativas y capaces de imponerse podrían hacer operativa una institución de este tipo“. Habermas plantea que la propia organización del mundo tiene que ser capaz de percibir de "un modo más efectivo y menos selectivo que hasta ahora, las tareas del aseguramiento internacional de la paz y del aseguramiento global de los derechos fundamentales del hombre".

La afirmación habermasiana de que un ámbito público europeo sólo podrá surgir cuando estén abiertos entre sí los diversos espacios públicos nacionales, nos hace pensar en su validez y uso en un contexto de comunicación que trascienda las fronteras nacionales y en una ciudadanía global o en una "transnacionalización de espacios públicos", terminología que Habermas (2009: 90) recoge de Bernhard Peters. Éste distingue tres grados de posibilidad comunicativa de participación: en relación a la acción de gobierno, por cuanto solo podrá tener lugar bajo una observación 
pública si "los medios de comunicación de masas nacionales despiertan la atención mediante informes y comentarios constantes, hacia las políticas y alternativas de decisión correspondientes"; en relación a los ciudadanos y su participación, estimado que solo encontrarán un acceso "si son informados por los medios también sobre las tomas de posición y el curso de las discusiones que se producen en los respectivos ámbitos públicos de otras naciones"; en relación al desarrollo de una voluntad deliberativa, "únicamente podrá desarrollarse si en los distintos ámbitos públicos intercomunicados puede realizarse un intercambio discursivo de argumentos y opiniones que trasciendan los límites nacionales". La oportunidad que inaugura este espacio se verá definitoriamente imposibilitada si no hay antes una corresponsabilidad ejecutante de y entre los actores de la gestión política y de la gestión informativa. Retomando a Habermas (2009: 90-91):

Para que los ciudadanos hagan uso, de hecho, de su derecho a elegir y para que en el curso de esta praxis ellos puedan formarse una conciencia de co-pertenencia, los procesos de decisión [europeos] tendrán que hacerse visibles y accesibles en los ámbitos públicos de cada nación (...) la idea jerárquica de una superposición de espacios públicos nacionales mediante un espacio público [europeo] que los abarque a todos con sus propios medios de comunicación, por lo general en lengua inglesa, va en la falsa dirección.

Si somos, utilizando la expresión empleada por Held, comunidades de destino solapadas participadas del mismo destino político ¿qué nos hace pensar que el sentimiento de copertenencia es un asunto del estado-nación y éste su punto de partida y de llegada?

Hay ejemplos extraordinarios en sentido contrario por mucho que su magnitud y alcance no tengan la cobertura informativa debida ni veamos dirigirse a su encuentro a los representantes de la política mundial. El surgimiento de un contexto de comunicación que trasciende las fronteras nacionales, bien puede constituirlo el Foro de Porto Alegre reunido hace pocas semanas para discutir Río+20 -la Conferencia de la ONU sobre Desarrollo Sustentable del próximo mes de junio en Río de Janeiro, transcurridas dos décadas desde la celebración de la primera- y para establecer los trabajos previos a la Cumbre de los Pueblos - una conferencia que las organizaciones de la sociedad civil realizan en paralelo a la Conferencia Intergubernamental de Naciones Unidas-. Dicho esto, nos interesaba establecer la percepción y el efecto que genera en los medios de comunicación. El Profesor Boaventura de Sousa Santos, publicó a propósito un artículo titulado Río+20 y la Cumbre de los Pueblos en Página 12 de Argentina, el día 13 de febrero de 2012. Dice: "El modo en que los grandes medios de comunicación trataron dos acontecimientos -el Foro Económico Mundial de Davos y el Foro Social Temático de Porto Alegre- es revelador de los intereses que hoy controlan a la opinión pública mundial.". Y recogemos también:

El primero mereció atención, pese a que nada nuevo se discutió allí: sólo análisis gastados sobre la crisis europea y la misma insistencia en rumiar los mismos síntomas de la crisis, ocultando las verdaderas causas. El segundo fue completamente omitido, 
pese a que se discutieron los problemas que condicionan en forma decisiva nuestro futuro: el cambio climático, el acceso al agua; la calidad y la cantidad de los alimentos disponibles ante las plagas del hambre y la desnutrición, la justicia ambiental; los bienes comunes de la humanidad y la validez de los conocimientos populares, no eurocéntricos, en la búsqueda de la justicia ambiental.

Recoge muy bien el artículo la tensión entre deliberación y negociación. Es interesante porque precipitaría un estudio de caso sobre la voluntad de actuar por el bien común de quienes nos gobiernan y a quiénes se deben, en realidad. Lo que nos pondría en la pista de abrir otro estudio de caso sobre la democracia y la práctica de diálogo cívico "donde uno comienza a escuchar y saber acerca del "otro", a ver por los ojos de los otros, y a reconocer y ampliar nuestros propios principios y valores" (Arenas-Dolz, 2008).

¿No sería urgente (y sólo eso sería política) ocuparse de los asuntos "reales" con menos "discreción de bibliófilo"?, se preguntaba Jacques Derrida (2005: 4583) al abordar su propuesta El futuro de la profesión o la universidad sin condición (gracias a las "humanidades", aquello que podría tener lugar mañana). Queríamos, para finalizar, aludir al sentido de las humanidades en la comunicación y el desarrollo. No eludir, en cualquier caso, el compromiso que también la filosofía alienta con otros modos de conocimiento y prácticas. Rescatamos un trabajo desarrollado por Christoher Fynsk (2005: 199-222). Con la idea de "acompañar" a Jacques Derrida aborda los escritos que éste realizase sobre la institución de la filosofía ${ }^{19}$. Los signos que según Derrida constituyen una nueva demanda de la filosofía son:

a) Una nueva configuración global de los asuntos éticos y jurídicos ("que han emergido con el fenómeno moderno: el error nuclear, el totalitarismo, el genocidio y la tortura, la urbanización y la catástrofe ecológica, y asuntos de salud mundial como la pandemia del sida); "asuntos globales para los cuales los conceptos fundacionales de la moralidad y la ley (ya sacudidos por críticas emanadas de la filosofía y el psicoanálisis) han demostrado ser profundamente inadecuados".

b) Desarrollos técnico-científicos desafiantes de conceptos tradicionales como la vida y la muerte (como en la tecnología médica) o del espacio y el tiempo (como los desarrollos en los medios y en la comunicación, "transformaciones que alteran el significado y la constitución misma del "espacio público").

c) Un surgimiento de los movimientos religiosos y de las fuerzas políticas asociadas a lo largo del mundo "que plantea nuevas forma de presión sobre los valores de la "razón" o sobre nociones tales como democracia";

d) Desplazamientos "culturales, "transformaciones en las artes y sus bases materiales, o transformaciones en las formas de vida”.

\footnotetext{
19 Particularmente nos aboca a dos ensayos: "Titres" y "Envois", surgidos del esfuerzo de Derrida por "ayudar a crear y encaminar” el Collège International de Philosophie.
} 
Derrida formula la hipótesis de que los muchos signos a los cuales se ha referido, signos que solicitan filosofía sin ser para la filosofía, no puedan estar acompañados por un discurso establecido. El colapso de la tradicional posición de "sobrearqueo" de la filosofía la expone "a la necesidad de repensar su relación con los múltiples órdenes de conocimiento y práctica". Debe encontrar su implicación en ellos "incluso mientras piensa sus papeles en ella" y debe encontrar nuevas formas de compromiso con las transformaciones "que no se rindan al poder sintetizador del concepto". Éste debía ser el horizonte, "la destinación", de la nueva institución Collège International de Philosophie, una intervención estratégica para comprometer los límites de la filosofía en sí - tal como plantea Fynsk del ejercicio propositivo de Derrida-. El pensamiento de la destinación es un pensamiento de otra historicidad. Fynsk lo expresa diciendo que es "un pensamiento de la coyuntura en sí, un pensamiento de las "con" y "dis" yunciones que marcan la relación de la filosofía consigo misma y con otro orden de discurso y de práctica, pero también un pensamiento del tiempo de estas exposiciones, un pensamiento de su acontecimiento". Las alusiones al pensamiento de otra historicidad no le son ajenas al lenguaje: "Antes de los tiempos conocidos, antes de que se alzaran las cordilleras de los tiempos históricos, hubo de extenderse un tiempo de plenitud que no daba lugar a la historia. Y si la vida no iba a dar a la historia, la palabra no iría tampoco a dar al lenguaje, a los ríos del lenguaje" (Zambrano, 1971: 81). Como tampoco las condiciones de posibilidad de la justicia y de la comunicación.

Devolver el orgullo y la autoestima a los perdedores de la sociedad fue una plataforma central de las reformas sociales que marcaron el progreso del siglo XX. Hoy les hemos dado la espalda de nuevo.

Tony Judt. Algo va mal

\section{CONCLUSIONES}

1. (Re)pensar el escenario actual en el orden de sus efectos - crisis económicofinanciera, medioambiental, alimentaria, de la democracia representativa, de la inequidad galopante, de la dominación cultural...- nos convoca a (re)pensar la capacidad transformadora de la comunicación, a día de hoy asimilada interesadamente a un plano potencial o a una posibilidad, que conmueve e impresiona pero no sanciona. Hacer este ejercicio de desenmascaramiento de la sociedad de la información, creemos, se convierte en un asalto al poder de la realidad. Y conviene realizarlo con carácter de urgencia.

2. Sin la articulación de todos los procesos relacionados con el derecho a la comunicación, la construcción de sociedades democráticas seguirá siendo solamente un "acto de compromiso". Se requiere entre todos los actores un trabajo de cooperación de voluntad y de fines para introducir en las agendas y estrategias nacionales la comunicación como ejercicio deliberativo que nos educa en el vivir juntos, en el conocer, en el hacer y en el ser: aprendizajes participados de la comunicación. 
3. Si la cultura del diálogo consigue penetrar y servir de guía a las instituciones y procesos de la cooperación para el desarrollo y la ciudadanía global, podrá fomentarse primero, voluntad deliberativa y, solamente después, procesos de transformación social - todo lo otro, estará como siempre en el decurso de la negociación - como abordaje de las diferencias, asimetrías, brechas y abismos del actual orden mundial. Se habrá configurado, de conseguirse, otro marco: entre las "condiciones de posibilidad" del desarrollo humano se situará, entonces, la comunicación, que le pone rostro. No intentarlo, al menos, supone reincidir en inercias reproductoras de inequidades o en distopías.

\section{REFERENCIAS BIBLIOGRÁFICAS}

ACosta, Alberto y MARTíNEZ, Esperanza (comp.) (2009): El buen vivir. Una vía para el desarrollo. Santiago:.Editorial Universidad Bolivariana.

Alfaro, Rosa María (2006): Otra brújula. Innovaciones en Comunicación y Desarrollo, Perú:.Calandria.

Arenas-Dolz, Francisco (2008): "Retórica Aristotélica y Democracia Deliberativa", Sistema. Revista de Ciencias Sociales. 206. Septiembre: 91-110.

Arenas-Dolz, F. y Pérez Zafrilla, P. J. (2010): "Retórica deliberativa y Racionalidad práctica. La rehabilitación de la argumentación pública en la vida política", Revista Española de Ciencia Política, 22. Marzo: 29-48.

BECERRIL MARTíNEZ, Walys (2009): "El derecho humano a comunicar: un copto amplio y flexible", Portal de la Comunicación. Incom-UAB.

(http://www.portalcomunicacion.com/monograficos_det.asp?id=181).

BELTRAN, Luis Ramiro (2007): "El pensamiento latinoamericano sobre comunicación democrática", Medios de Comunicación. El escenario iberoamericano. Madrid: Ariel, Fundación Telefónica.

BRUDTLAND, Gro Harlem (1987): Nuestro futuro común, WCED.

ButLER, Judith (2006): Vida precaria (El poder del duelo y la violencia), Buenos Aires: Paidós.

BuRguI, Teresa y ERRo, Javier (coord.) (2010): Comunicando para la solidaridad y la cooperación. Comunicación, Educación y Ciudadanía y Gobierno de Navarra. Pamplona: Foro.

CASTELLs, Manuel (ed.) (2006): La sociedad Red: Una visión global, Alianza Editorial.

CoHEN, Tom (coord.) (2005): Jacques Derrida y las humanidades. Un lector crítico. México: Siglo XXI.

Delmas-Marty, Mireille (2011): "Entrevista Jasmina Sopova" en El Correo de la UNESCO. Octubre-Diciembre: 28-32.

DERRIDA, Jacques (1997): Anne Dufourmantelle invite Jacques Derridaà repondre de l'hospitalité. Paris: Calmann-Levy.

FynsK, Christopher (2005) "Derrida y la Filosofía: Actos de Compromiso" en COHEN, Tom (coord.), Jacques Derrida y las humanidades. Un lector crítico. México: Siglo XXI:. 199-222.

García Roca, Joaquín (2010): Comunicando para la solidaridad y la cooperación. Pamplona: Foro comunicación y Ciudadanía y Gobierno de Navarra, en BurgUI, T. y J. ERRO (coord). 
(2010): Comunicando para la solidaridad y la cooperación. Pamplona: Foro Comunicación, Educación y Ciudadanía, y Gobierno de Navarra.

GuMUCiO Dagron (2004): "El cuarto mosquetero: la comunicación para el cambio social", Investigación y Desarrollo, 12-1.

Habermas, Jürgen (2009): ¡Ay, Europa! Pequeños escritos políticos XI. Madrid: Editorial Trotta.

Hamelink, Cees J. (2002): Hacia la Cumbre Mundial sobre la Sociedad de la Información. El derecho humano a comunicarse. (Disponible en www.infoamerica.org).

Harms, L. S. (2002): "Some Essentials of the Right to Communicate". (Disponible en http://www.righttocommunicate.org/viewDocument.atm?sectionName=collection\&id= 35 [recuperado noviembre 2011].

Held, David (2005): Pacto Global. Madrid: Taurus.

JiMÉNEZ LOZANO, José (1990): “La reconstrucción del recuerdo”. La balsa de la medusa, 14: 3-15. JuDT, Tony (2011): Algo va mal, Madrid: Taurus.

KaPlúN, Gabriel (2007): "Comunicación comunitaria". Medios de Comunicación. El escenario iberoamericano. Madrid: Ariel, Fundación Telefónica, 311-320.

KAPLÚN, Mario (1998): Una pedagogía de la comunicación. Madri: Ediciones la Torre.

Karavanta, Asimina (2011). “¿Y la hospitalidad?” en El Correo de la UNESCO. OctubreDiciembre: 14-16.

MacBride, Sean AND Others (1980): Many Voices, One World. París: UNESCO..

MARTíneZ, Raquel y LuBEKIN, Mario (2011): Comunicación y Desarrollo: politicas, redes y tecnologías. AECID, IPS, UIMP.

MATtElART, Armand (2009): “De una crisis a otra. De una utopía a otra". Telos, 81: 99-102.

Morin, Edgard (2010): "Elogio de la metamorfosis", El Pais, 17 de enero.

Murciano, Marcial et ALT. (2009): La prensa y la cooperación para el Desarrollo. Aecid, IPS, UIMP, Comunicación Social.

OCDE (2011): Divided we Stand: Why Inequality Keeps Rising, (http:/www.oecd.org/document/51/0,3746,en_2649_33933_49147827_1_1_1_1,00.html) [consultado abril 2012].

RAMONET, Ignacio (2011): El "nuevo sistema-mundo". (Disponible en: www.othernews.info/noticias) [Consultado noviembre 2011].

RIsT, Gilbert (2002): El Desarrollo: historia de una creencia occidental. Madrid: IUDCCatarata.

Rocha, Manuel de la (2011): "La riqueza cambiante de las naciones". El País, 8 de enero.

RoIz, Javier (2003): La recuperación del buen juicio. Teoría política en el siglo veinte. Madrid: Editorial Foro Interno.

(2002): “La teoría política de Hannah Arendt (1906-1975)", WP, 208, Barcelona: Institut de Ciences Politiquees i Socials.

(2000): “La teoría política de Eric Voegelin", Revista de Estudios Políticos (Nueva Época), 107.

SAVIO, Roberto (2011): "Vivir el Nuevo Orden Informativo Internacional", Encuentro Comunicación y desarrollo: nuevos escenarios. SantandeR: UIMP.

Sen, Amartya (2000): Desarrollo y libertad., Barcelona: Planeta.

Sotelo, Ignacio (1999): "La palabra libre”. El País, 20 de septiembre.

Sousa Santos, Boaventura de (2012): "Río +20 y la Cumbre de los Pueblos". Página 12 de Argentina, 13 de febrero. (Disponible en www.other -news.info/noticias) [Consultado febrero 2012]. 
STIGLitz, Joseph (2011): La cura para la economía. (Disponible en: www.othernews.info/noticias) [Consultado octubre 2011].

Velasco, Juan Carlos (2009): "Democracia y deliberación pública" en Confluencia XXI. Revista de Pensamiento Político,6: 70-79.

VIRILIO, Paul (1997): El cibermundo. La politica de lo peor, Madrid: Cátedra.

ZAMBRANO, María (1971): Obras reunidas, Madrid: Aguilar.

\title{
RESUMEN
}

Entre las "condiciones de posibilidad" del desarrollo humano se sitúa la comunicación, que le pone rostro. Los pliegues del mapa infocomunicacional que hoy nos entrelaza definen un espacio compartido de medios tradicionales — sociedad de masas - y medios interactivos — sociedad digital-. Una urdimbre también tejida por una ciudadanía que se asocia y construye derechos. Sobre este mapa, el desarrollo ha venido a ser emplazado desde variadas y variables localizaciones o dominios de sentido: Sociedad Postindustrial (Bell), Sociedad Informacional y Sociedad Red (Castells), Sociedad Tecnocientífica (Virilio), Sociedad Tecnológica Avanzada (Negroponte), Sociedad de la Información (OCDE), Sociedad Digital del Conocimiento (Unión Europea). Todas han construido topografías del desarrollo, y por lo tanto del conocimiento, la información y la comunicación. Más de cuatro décadas de aporte teórico sobre este mapa de la comunicación en el desarrollo ponen de manifiesto la pertinencia de reabrir los debates de la democratización de la información (MacBride) y del derecho de los pueblos a comunicarse (Hamelink), por cuanto estamos donde estábamos en los setenta: ante la impermeabilidad de un orden transferente tecnológico que afianza (y sostiene) parecidas y similares asimetrías y diferencias estructurales. De tal modo, que la distancia entre unos y otros que ayer era brecha, hoy ya es abismo.

Palabras clave: Derecho a la comunicación, desarrollo humano, transformación social, cooperación y democratización de la información.

\begin{abstract}
Communication is one of the "conditions of possibility" of Human Development. The folds of the infocommunicational map, that is linking us today, define a share space between mainstream media (mass society) and social media (digital society). An intricate space which is also weaved by associated citizenship or individuals who are constructing the right to communication. On this map, development has been located from several and different places or spheres of sense: Postindustrial Society (Bell), Informational and Network Society (Castells), Techno-sciences Society (Virilio), Advanced Technology Society (Negroponte), Information Society (OCDE), or Digital Society of Knowledge (European Union). All of them have constituted topographies of development, and consequently, of knowledge, information and communication. These four decades of theoretical contributions to the map of communication in development show the pertinence of reopening the debate about democratization of information (Mcbride) and the people's right to communicate (Hamelink) because we are in the same place as we were in the seventies: behind the impermeability of a technological transfer order that consolidates (and maintains) similar asymmetries and structural differences.
\end{abstract}

Key words: The people's right to communicate, human development, social transformations, cooperation, democratization of information. 


\section{RÉSUMÉ}

Communication est l'un des (conditions de possibilité) de développement humain. Les plis de la carte de l'info-communication, qui est devant nous aujourd'hui, définissent un espace de partage entre les médias de (société massive) et les médias sociaux (société digitale). Un espace complexe, qui est également construit par la citoyenneté ou des personnes qui construisent le droit à la communication. Sur cette carte, le développement a été localisé dans plusieurs et différents endroits ou sphères de sens : la société postindustrielle (Bell),l' informationnel et Network Society (Castells), les techniques-sciences de la société (Virilio),la société de technologie avancée (Negroponte), la société de l'Information (OCDE) ou digitale, la société de la connaissance (Union européenne). Toutes ont constitué des topographies du développement et par conséquent, des connaissances, d'information et de communication. Ces quatre décennies de contributions théoriques à la carte de communication et développement montrent la pertinence de la réouverture du débat sur la démocratisation de l'information (McBride) et le droit des personnes a communiquer (Hamelink), parce que on est toujurs au meme espace ou on était aux années septante: devant l'impermeabilité d'un ordre que consolide et mantient asymmetries et differences structurales semblables .

Mots clé: Droit des personnes à la communication, développement humaine, transformations sociales, cooperation, democratization de l' information. 